\author{
久門 良明，渡邊 英昭，伊賀瀬圭二，長戸 重幸 \\ 福本 真也，岩田 真治，大上 史朗，大西 丘倫
}

\title{
Surgical Results in Patients with Unruptured Asymptomatic Cerebral Aneurysms: Significance of Evaluation of Neuropsychological Function, Magnetic Resonance Images and Cerebral Blood Flow
}

Yoshiaki Kumon, M.D., Hideaki Watanabe, M.D., Keiji Igase, M.D., Shigeyuki Nagato, M.D., Shinya Fukumoto, M.D., Shinji Iwata, M.D., Shiro OHue, M.D., and Takanori OHNishi, M.D.

Department of Neurosurgery, Ehime University School of Medicine, Toon, Japan

Summary: We evaluated neuropsychological function, magnetic resonance (MR) images and cerebral blood flow (CBF) in patients with unruptured asymptomatic cerebral aneurysms.

Among consecutive operations $(n=73)$ on 70 patients since 2000, direct surgery was performed in 53 operations on 50 patients, and intravascular surgery was performed in 20 operations on 20 patients. Surgical results of direct surgery were studied. Direct surgery was selected mainly for patients with small and anterior circulation aneurysms. MR imaging was conducted 1 week after surgery, and Wechsler Adult Intelligence Scale-Revised (WAIS-R) examination and CBF measurement using ${ }^{133} \mathrm{Xe}-$ SPECT were done before and 1 month after surgery.

Abnormal neurological findings were recognized postoperatively in $26 \%$ of surgeries. Among them, visual disturbance was permanent in $4 \%$ of surgeries, all of which were surgeries for paraclinoid internal carotid artery aneurysms. WAIS-R results deteriorated in $26 \%$ of surgeries at 1 month and at least in $5 \%$ of surgeries at 1 year after surgery. MR images at 1 week after surgery revealed brain damage in $30 \%$ of surgeries and subdural fluid collection in $19 \%$ of surgeries. Patients with large brain damage or thick subdural fluid collection frequently showed neurological deficits and/or WAIS$\mathrm{R}$ deterioration. These complications were recognized frequently in patients with ACoA aneurysms. Resting CBF decreased significantly in the area supplied by the anterior cerebral artery and anterior border zone on the operated side postoperatively. The brain damage and subdural fluid collection were observed frequently and caused neurological deficits and neuropsychological dysfunction, although these were usually transient.

It may be necessary to evaluate neuropsychological function, MRI and CBF in patients with unruptured asymptomatic cerebral aneurysms to improve surgical results.

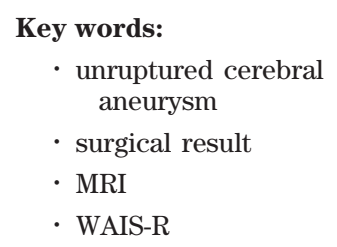

Surg Cereb Stroke

(Jpn) 34: 434-439, 2006 


\section{緒 言}

無症候性未破裂脳動脈瘤の治療成績については, 直達手

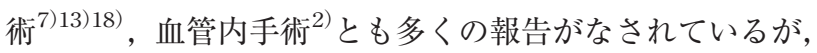
morbidity P mortalityに加え, より詳細な評価が望まれ る.われわれも当施設での連続症例の手術成績を検討し, 直達手術では術後高次脳機能の低下や画像上の異常所見が 予想以上に高率に認められること，また血管内手術では無 症候性にMRI 拡散強調画像上で脳塞栓が認められること を報告した ${ }^{1112) 14)}$. 今回，その後の症例を加えて直達術 の手術成績を検討するとともに，術後の神経症状，高次脳 機能障害, MRI上の異常所見や脳血流変化の関連を検討 し，その意義を明らかにした。

\section{対象および方法}

当施設で治療した 2000 年以降の無症候性未破裂脳動脈 瘤は 70 例・ 73 件で，瘤検出の理由は，頭痛・眩量などの 精査が 55 例 (79\%) と大半を占め, 他の脳疾患 (脳梗塞, 脳 血管奇形, 頭部外傷)の精査が 6 例, 他部位の脳動脈瘤破 裂が 4 例, 脳ドックが 5 例であった.

当施設での手術適応は，75歳未満で全身麻酔に支障と なる全身性疾患や悪性疾患が認められず, 瘤の最大径が 3 $\mathrm{mm}$ 以上の処置可能な例としている, 手術法は, 椎骨脳底 動脈 (VA - BA) 系瘤や動脈輪近傍部内頸動脈 (ICA) 瘤は 血管内手術を, それ以外の ICA 系の瘤は直達手術を第一 選択とした。 その結果, 直達手術群は 50 例・ 53 件, 血管 内手術群は 20 例 $\cdot 20$ 件であり, 直達手術例を今回の対象 とした。な打直達手術はY.K.を中心に卒後 10 年以上の脳 神経外科学会専門医が行った。瘤部位は, ICA系の瘤が ほとんどで，1例を除き小さな瘤であった(Table 1).な 打多発例は ICA + MCA が 2 件， $\mathrm{ACoA}+\mathrm{MCA} ， \mathrm{BA}+$ MCA が1件ずつであった。直達手術では, clippingを 48 件, coating 5 件行った。

手術結果の評価は, 神経症状とともにWechsler Adult Intelligence Scale-Revised (WAIS-R), MRI所見, 脳血流 所見を検討した。WAIS-R は，術前と術後 1 カ月目に，2 名の臨床心理士が行い, 術前に比べ術後の全検査 intelligence quotient (IQ) が測定標準誤差 ${ }^{16)}$ の 3 点以上低下し た場合を悪化と判定した。MRIは，術後 1 週目に fluidattenuated inversion recovery 法で撮像し, 脳損傷の評価 は，病変の広がりが 2 スライス以上存在するものを large, 1スライスのみのものを small とした。また硬膜下液貯留 を認めた例では主にCTでフォローし，明らかな脳圧迫所 見を伴うものを thick, 伴わないものを thin とした (Fig. 1).

脳血流検査は ${ }^{133} \mathrm{Xe}$ 吸入法 SPECT を用い, 術前と術後
Table 1 Patient's characteristics

\begin{tabular}{lc}
\hline Sex & Male: 18 Female: 32 \\
Age (y.o.) & $34-76(57.4)$ \\
Systemic diseases & \\
HT, DM, HL & 28 \\
CVD & 2 \\
Site of aneurysm & \\
ACoA & 14 \\
MCA & 15 \\
ICA & 16 \\
ACA & 2 \\
PCA & 2 \\
Multiple & 4 \\
Size of aneurysm & \\
small & \\
large & 56 \\
giant & 1 \\
mean (mm) & 0 \\
\hline
\end{tabular}

$H T$, hypertension; DM, diabetes; $H L$, hyperlipidemia; CVD, cerebrovascular disease; $A C O A$, anterior communicating artery; MCA, middle cerebral artery; ICA, internal carotid artery; $A C A$, anterior cerebral artery; PCA, posterior cerebral artery; VA, vertebral artery; BA, basilar artery; small, <13 mm; large, 13-25 mm; giant, $25 \mathrm{~mm}<$

1 カ月目に, 安静時およびAcetazolamide $1 \mathrm{~g}$ 静注 15 分後 に行った。装置はSPECT2000H-40 (日立，東京)を使用し た。高感度コリメーター(空間分解能はfull width at half maximum として $21.3 \mathrm{~mm}$ )にてダイナミック SPECT 収集 を行い(各 20 秒で 16 scan), Kanno-Lassen 法により局所 脳血流を算出した ${ }^{6)}$. OM line に平行に厚さ $12 \mathrm{~mm}$ で基底 核レベルょり半卵円中心までの 4 スライスの横断断面画像 を作成し，各断面に 12 力所 (左右半球各 6 力所)で計 48 力 所の関心領域を設け，局所脳血流量 $(\mathrm{rCBF})$ を求めた。 そ して各関心領域を左右の ACA 領域, anterior border zone (BZ), MCA 領域, posterior border zone (BZ), PCA 領域に分けて術前，術後の脳血流を比較した。なお interhemispheric approach例では, 両側半球を手術側と 考え，両側各領域の平均值を求めた。また脳血管反応性と して, Acetazolamide負荷後の血流増加率 (\% Increase)を $[\mathrm{rCBF}($ Acetazolamide) $-\mathrm{rCBF}$ (Rest) $] / \mathrm{rCBF}$ (Rest) $\times$ 100 (\%)で算出した.

なお統計学的判定には Mann-Whitney’s U testないし Paired t test を用い，それぞれ危険率 $5 \%$ 以下を有意と判 定した. 

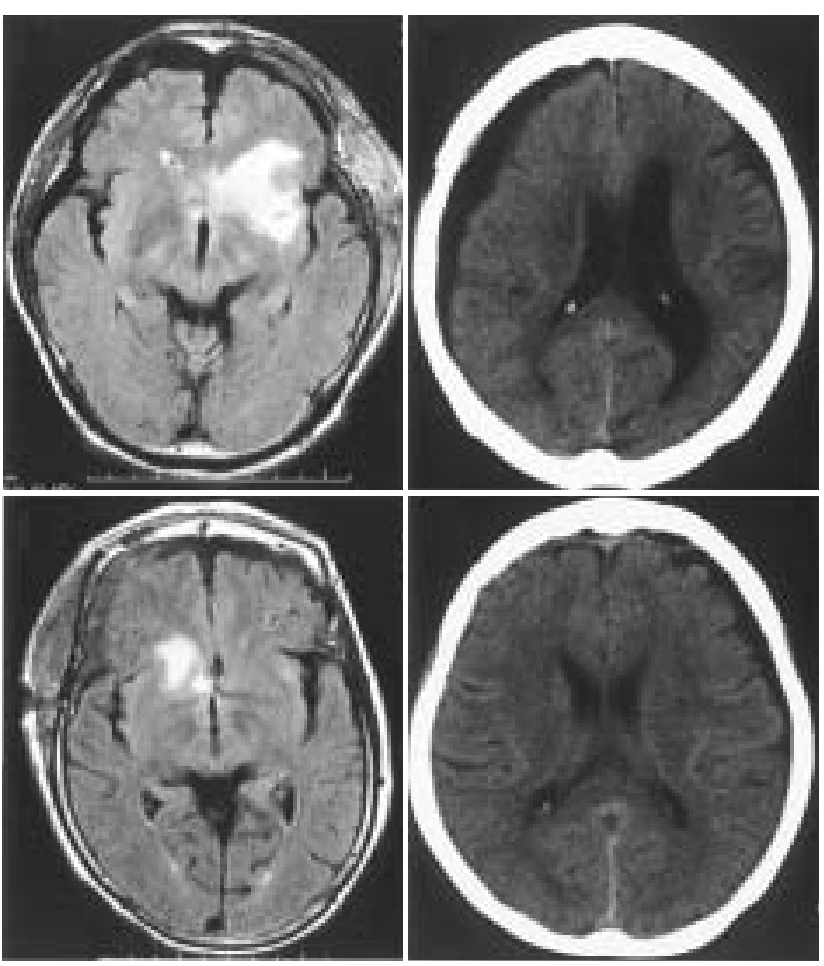

Fig. 1 Classification of brain injury ( $\mathrm{A}$; large, $\mathrm{B}$; small) on MR $A \mid C \quad$ images and subdural fluid collection $(C$; thick, $D$; thin)

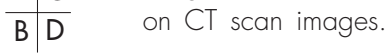

Table 2 Postoperative neurological deficits and deterioration of WAIS-R results

\begin{tabular}{|c|c|c|c|c|}
\hline & \multicolumn{2}{|c|}{ Neurological deficits } & \multicolumn{2}{|c|}{ Deterioration of WAIS-R results } \\
\hline & + & - & + & - \\
\hline ACoA & $4(27 \%)$ & $10(73 \%)$ & $3(27 \%)$ & $8(73 \%)$ \\
\hline MCA & $4(27 \%)$ & $11(73 \%)$ & $4(40 \%)$ & $6(60 \%)$ \\
\hline ICA & $3(19 \%)$ & $13(81 \%)$ & $1(7 \%)$ & $13(93 \%)$ \\
\hline ACA & $0(0 \%)$ & $2(100 \%)$ & $0(0 \%)$ & $2(100 \%)$ \\
\hline PCA & $2(100 \%)$ & $0(0 \%)$ & $2(100 \%)$ & $0(0 \%)$ \\
\hline Multiple & $1(25 \%)$ & $3(75 \%)$ & $1(25 \%)$ & $3(75 \%)$ \\
\hline Total & $14(26 \%)$ & $39(74 \%)$ & $11(26 \%)$ & $32(74 \%)$ \\
\hline
\end{tabular}

結果

\section{1. 神経症状と高次脳機能}

術後なんらかの神経症状を 14 件 (26\%)に認め，軽度の 意識障害や見当識障害が 5 件, 痤攣 4 件, 視力障害 3 件, 失語症 1 件，片麻痺 1 件であった。そのうち視神経障害の 2 例 (4\%)で永続し, 退院時 modified Rankin Scale はとも に1であった。 ICA系の瘤部位別では，ACoA 瘤と MCA 瘤では，軽度意識障害や痤攣が，それぞれ 4 件 $(27 \%)$ と高 頻度であったがいずれも一過性であった。一方 ICA 瘤で は，視力障害を 3 件 $(19 \%)$ に認め， 2 件で先述のように永 続したが，動脈輪近傍の瘤であった(Table 2).

WAIS-Rは 43 件で術前後に実施しえた。平均 score は 95.3 から 96.9 と術後増加したが，個々でみると 11 件 $(26 \%)$ で悪化した。 1 年後に再検査を実施しえた 8 件のうち 2 件 (AcoA，PCA瘤)が悪化のままであった。瘤部位別では, MCA 瘤 40\%, ACoA 瘤 27\% と高頻度であった (Table 2).

\section{2. 脳損傷}

MRI上の脳損傷を 16 件 (30\%)に認め, large と small が 8 件ずつであった。瘤部位別では，ACoA瘤で $50 \%$, $\mathrm{MCA}$ 瘤で $26 \%$ と高頻度であった。また硬膜下液貯留を 10 件 (19\%)に認め, thick 4 件, thin 6件であった。瘤部 位別では，ACoA瘤で $35 \%$ と多く， ICA 瘤では 1 件もな かった。多くは経過観察で消失ないし縮小したが，thick の $\mathrm{ACoA}$ 瘤 1 例で痴呆と歩行障害が出現し脳室拡大を伴 ったため，1 カ月半後に脳室腹腔短絡術を行った (Table 3).

脳損傷が神経症状や高次脳機能に及ぼす影響をみると， large 例では神経症状を 63\% に，WAIS-R 悪化を $86 \%$ に認 め，脳損傷のなかった例に比して有意に高頻度であった (Table 4). なお WAIS-R 悪化を 1 年後も認めた 2 例は脳 損傷が large であった。また硬膜下液貯留では, thick 例 ではなんらかの神経症状を 50\%に，WAIS-R 悪化を $75 \%$

Table 3 Postoperative brain injury and subdural fluid collection

\begin{tabular}{lccccccc}
\hline & \multicolumn{3}{c}{ Brain injury } & & \multicolumn{3}{c}{ Subdural fluid collection } \\
\cline { 2 - 3 } & large & small & - & & thick & thin & - \\
\hline ACoA & $3(21 \%)$ & $4(29 \%)$ & $7(50 \%)$ & & $2(14 \%)$ & $3(21 \%)$ & $8(73 \%)$ \\
MCA & $2(13 \%)$ & $2(13 \%)$ & $11(74 \%)$ & & $1(7 \%)$ & $1(7 \%)$ & $6(60 \%)$ \\
ICA & $0(0 \%)$ & $1(6 \%)$ & $15(94 \%)$ & & $0(0 \%)$ & $0(0 \%)$ & $13(93 \%)$ \\
ACA & $0(0 \%)$ & $0(0 \%)$ & $2(100 \%)$ & & $0(0 \%)$ & $0(0 \%)$ & $2(100 \%)$ \\
PCA & $2(100 \%)$ & $0(0 \%)$ & $0(0 \%)$ & & $1(50 \%)$ & $0(0 \%)$ & $0(0 \%)$ \\
Multiple & $1(25 \%)$ & $1(25 \%)$ & $2(50 \%)$ & & $0(0 \%)$ & $2(50 \%)$ & $3(75 \%)$ \\
\hline Total & $8(15 \%)$ & $8(15 \%)$ & $37(70 \%)$ & & $4(8 \%)$ & $6(1)$ & $43(81 \%)$ \\
\hline
\end{tabular}


Table 4 Relationship between brain injury and neurological deficits or brain injury and WAIS-R results

\begin{tabular}{lcccccc}
\hline & \multicolumn{2}{c}{ Neurological deficits } & & \multicolumn{2}{c}{ WAIS-R deterioration } \\
\cline { 2 - 3 } \cline { 6 - 7 } & + & - & & + & - \\
\hline Large injury $(n=8)$ & $5(63 \%)^{*}$ & $3(37 \%)$ & & $6(86 \%)^{* *}$ & $1(14 \%)$ \\
Small injury $(n=8)$ & $1(13 \%)$ & $7(87 \%)$ & & $2(33 \%)$ & $4(67 \%)$ \\
No injury $(n=37)$ & $8(22 \%)$ & $29(78 \%)$ & & $4(13 \%)$ & $26(87 \%)$ \\
\hline Total & $14(26 \%)$ & $39(74 \%)$ & & $12(28 \%)$ & $31(72 \%)$ \\
\hline
\end{tabular}

Occurrence of neurological deficits in patients with large injury was significantly higher than those in patients with small injury or no brain injury $\left.1^{*} p<0.05\right)$. Occurrence of WAIS-R deterioration in patients with large injury was significantly higher than that in patients without brain injury $\left({ }^{* *} p<0.01\right)$.
Table 5 Relationship between subdural fluid collection and neurological deficits or subdural fluid collection and WAIS-R results

\begin{tabular}{lccccccc}
\hline & & \multicolumn{2}{c}{ Neurological deficits } & & \multicolumn{2}{c}{ WAIS-R deterioration } \\
& & + & - & & + & - \\
\hline Thick & $(n=4)$ & $2(50 \%)$ & $2(50 \%)$ & & $3(75 \%)^{*}$ & $1(25 \%)$ \\
Thin & $(n=6)$ & $2(33 \%)$ & $4(67 \%)$ & & $3(50 \%)$ & $3(50 \%)$ \\
None & $(n=43)$ & $10(23 \%)$ & $33(77 \%)$ & & $6(18 \%)$ & $27(82 \%)$ \\
\hline Total & & $14(26 \%)$ & $39(74 \%)$ & & $12(28 \%)$ & $31(72 \%)$ \\
\hline
\end{tabular}

Occurrence of WAIS-R deterioration in patients with thick subdural fluid collection was significantly higher than that in patients without subdural fluid collection ( ${ }^{*} p<0.05$ ).

Table 6 Changes in cerebral blood flow and cerebrovascular response on the operated hemisphere Cerebral blood flow (ml/100 g/min)

\begin{tabular}{|c|c|c|c|c|c|c|c|c|c|c|}
\hline & \multicolumn{5}{|c|}{ Pre } & \multicolumn{5}{|c|}{ Post } \\
\hline & ACA & ant BZ & MCA & post BZ & PCA & ACA & ant BZ & MCA & post BZ & PCA \\
\hline Total & $41.7 \pm 4.7$ & $41.1 \pm 4.5$ & $39.7 \pm 4.2$ & $36.6 \pm 4.2$ & $40.2 \pm 4.6$ & $39.9 \pm 4.4^{* *}$ & $38.9 \pm 5.3^{* *}$ & $40.1 \pm 4.9$ & $36.7 \pm 4.6$ & $41.0 \pm 4.7$ \\
\hline $\mathrm{ACoA}$ & $40.5 \pm 3.9$ & $40.4 \pm 3.7$ & $38.6 \pm 3.2$ & $35.9 \pm 3.1$ & $39.2 \pm 3.3$ & $37.6 \pm 4.4^{*}$ & $36.6 \pm 5.3^{*}$ & $38.1 \pm 4.3$ & $34.6 \pm 4.5$ & $38.4 \pm 3.8$ \\
\hline MCA & $43.0 \pm 4.0$ & $41.4 \pm 4.8$ & $40.2 \pm 4.3$ & $37.2 \pm 4.6$ & $42.2 \pm 4.1$ & $40.7 \pm 4.4$ & $39.3 \pm 5.7$ & $40.6 \pm 6.1$ & $38.7 \pm 5.8$ & $43.6 \pm 6.8$ \\
\hline ICA & $43.4 \pm 5.4$ & $43.0 \pm 4.8$ & $41.3 \pm 5.0$ & $37.6 \pm 5.0$ & $40.6 \pm 5.8$ & $41.9 \pm 4.0$ & $40.9 \pm 4.8^{*}$ & $42.1 \pm 4.3$ & $37.6 \pm 3.4$ & $42.1 \pm 3.2$ \\
\hline
\end{tabular}

Cerebrovascular response $(\%)$

\begin{tabular}{|c|c|c|c|c|c|c|c|c|c|c|}
\hline & \multicolumn{5}{|c|}{ Pre } & \multicolumn{5}{|c|}{ Post } \\
\hline & ACA & ant BZ & MCA & post BZ & PCA & ACA & ant BZ & MCA & post BZ & PCA \\
\hline Total & $35.5 \pm 12.6$ & $39.0 \pm 14.1$ & $39.3 \pm 11.3$ & $42.5 \pm 12.8$ & $42.6 \pm 14.5$ & $34.6 \pm 13.7$ & $35.7 \pm 15.0$ & $37.1 \pm 14.1$ & $40.4 \pm 15.2$ & $38.6 \pm 14.8$ \\
\hline $\mathrm{ACoA}$ & $32.1 \pm 11.9$ & $31.4 \pm 10.7$ & $33.7 \pm 8.7$ & $35.9 \pm 8.5$ & $37.3 \pm 11.1$ & $36.5 \pm 13.9$ & $37.8 \pm 16.8$ & $39.2 \pm 14.3$ & $40.9 \pm 14.4$ & $41.1 \pm 15.6$ \\
\hline MCA & $34.0 \pm 15.0$ & $40.7 \pm 14.5$ & $40.4 \pm 12.4$ & $46.7 \pm 12.1$ & $42.0 \pm 15.0$ & $31.5 \pm 15.1$ & $31.6 \pm 15.4^{*}$ & $34.0 \pm 14.3$ & $34.1 \pm 16.8^{*}$ & $31.6 \pm 12.9$ \\
\hline ICA & $35.6 \pm 9.4$ & $40.6 \pm 14.1$ & $41.6 \pm 11.1$ & $42.9 \pm 13.3$ & $44.8 \pm 16.1$ & $33.9 \pm 14.8$ & $34.9 \pm 14.2$ & $36.9 \pm 15.3$ & $43.4 \pm 16.0$ & $40.4 \pm 16.0$ \\
\hline
\end{tabular}

$\mathrm{ACA}$, anterior cerebral artery; ant BZ, anterior border zone; MCA, middle cerebral artery; post BZ, posterior border zone; PCA, posterior cerebral artery; ACoA, anterior communicationg artery; MCA, middle cerebral artery; ICA, internal carotid artery

Resting CBF at ACA and ant BZ decreased significantly in total patients ( ${ }^{* *} p<0.01$ ). Resting CBF at ACA and ant BZ decreased significantly in patients with $A C O A$ aneurysm ( $\left.{ }^{*} p<0.05\right)$. Resting CBF at ant BZ decreased significantly in patients with ICA aneurysm ( $\left.{ }^{*} p<0.05\right)$. CVR at ant and post BZ decreased significantly in patients with MCA aneurysm $\left({ }^{*} p<0.05\right)$.

に認め，ない例に比してWAIS-R 悪化が有意に高頻度で あった(Table 5).

\section{3. 脳血流}

脳血流検查を 42 件で術前後に実施しえた。全例では安 静時脳血流は, 手術側の ACA 領域と anterior BZで術後 に明らかな低下を認めたが，脳血管反応性は全領域で低下 傾向を示すのみであった。瘤部位別では, ACoA 瘤では手 術側の ACA 領域と anterior BZで, ICA 瘤では手術側の anterior BZで安静時脳血流の明らかな低下を, MCA 瘤 では anterior BZ と posterior BZ で脳血管反応性の明らか な低下を認めた (Table 6).
術後の神経症状, WAIS-R, 脳損傷, 硬膜下液貯留のい ずれかの異常所見を認めた 21 件では, 安静時脳血流の低 下 (1S.D. $5 \mathrm{ml} / 100 \mathrm{~g} / \mathrm{min}$ 以上) と脳血管反応性の低下 (1S.D. 15\% 以上) あるいは安静時脳血流低下のみを示す場 合がそれぞれ 5 件 $(24 \%)$ と 7 件 (33\%)であり，いずれの異 常所見も認めなかった群の 3 件 (14\%)，2 件 (10\%)に比べ 血流低下を有意に多く認めた (Table 7).

\section{考察}

未破裂無症候性脳動脈瘤に対する直達術の手術成績は, King らによれば, morbidityは 4.1\%, mortality は 1.0\%で ある ${ }^{7)}$. 今回の結果では morbidityは 4.0\%, mortalityは 
Table 7 Postoperative changes in cerebral blood flow and cerebrovascular response in patients showing abnormal findings and those in patients showing normal findings

\begin{tabular}{lcccc}
\hline Decrease of CBF/CVR & $(-1 / 1-1$ & $(-1 / 1+1$ & $1+1 / 1-1$ & $(+1 / 1+1$ \\
\hline Patients showing abnormal findings & $3(14 \%)$ & $6(29 \%)$ & $7(33 \%)$ & $5(24 \%)^{*}$ \\
Patients showing normal findings & $8(38 \%)$ & $8(38 \%)$ & $2(10 \%)$ & $3(14 \%)$ \\
\hline
\end{tabular}

CBF, cerebral blood flow; CVR, cerebrovascular response

Abnormal findings mean neurological deficits, WAIS-R deterioration, brain damage, or subdural fluid collection. Occurrence of CBF decrease in patients showing abnormal findings was significantly higher than that in patients showing normal findings $\left({ }^{*} p<0.05\right)$.

0\%であった。しかし，直達手術の術後早期には，ほとん どは一過性であるが，不穏や傾眠傾向といった軽度の意識 障害や痤攣などの神経症状を経験する。波出石ら ${ }^{4)}$ は 18/72(25\%)に, 間中ら ${ }^{13)}$ は 39/112 例 (35\%)に, Yasui ら 18) は 35/312 例 (11\%)に認めたと報告しており，今回は 14 件 $(26 \%)$ に認めた。

高次脳機能に関する報告では, 検査方法と結果の判定法 の違いで頻度に差がある3)9-11)14)15)17). 術後 1 力月目に WAIS-R とともに前頭葉機能評価を実施しても全例でみれ ば悪化しなかったとの報告 ${ }^{15)}$ や, 術後脳障害を合併しな かった例では 3 カ月後には高次脳機能障害は認めなかった

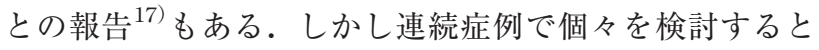
Fukunaga ら $^{3)}$ は33-57\%に，われわれも 6-31\%に仮名拾 いテストなどの術後悪化を認めた ${ }^{11)}$ 14). またWAIS-Rを 術後 50 日以降に実施した報告でも, 全患者では術前後に 変化はなかったが, 個々では $6 / 21$ 例 (29\%) に全検查 IQ の 3 点以上の低下を認めた ${ }^{9)}$. 今回の WAIS-Rでの結果も, 全例では術前後で変化なかったが, 個々では術後 1 力月で $26 \%$ が悪化し 1 年後で $5 \%$ は悪化のままであった。ただ， いずれの症例もわずかな記銘力低下を自覚するのみで術前 生活に復帰している.

直達手術後の MRIでみられる脳障害には, 静脈損傷や 脳圧排による挫傷, 硬膜下液貯留, 穿通枝障害による梗塞 がある. Jenkins らは破裂瘤 10 例の術後早期 MRI で全例 に脳浮腫や挫傷を認めた ${ }^{5)}$. また Kivisaariらは, 術後平 均 3.3 年の MRI で前頭側頭葉底面に 36/101例 (36\%)に脳 損傷を認め, 破裂瘤対側の未破裂瘤 10 例では破裂瘤の術 後 1-5 カ月に手術したが 1 例 (10\%) で同部に脳損傷を認め た。しかしこれら脳損傷と臨床症状との関連はなかったと 報告している8). 今回の検討では大きな脳損傷を 8 件(15\%) に認めたが, これらの例では術後の神経症状や高次脳機能 障害を高頻度に伴うことが明らかとなった。また硬膜下液 貯留を 10 件 (19\%)に認め, 圧迫所見を伴う 4 件 (8\%)では, 術後の高次脳機能の悪化が高頻度であった。

脳循環への影響は, 半球平均值では術前後に差はなかっ

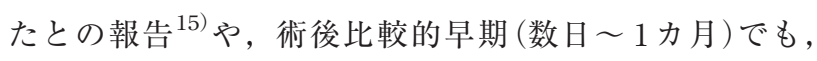

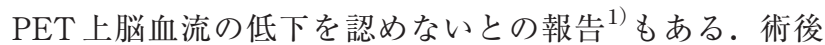
に脳損傷や硬膜下液貯留を伴わない例では脳循環への影響 はないと思われる.しかし連続症例を検討したFukunaga らは術後 1 力月の ECD-SPECT で ICA 系瘤 26 例中 9 例に, 手術側前頭葉や側頭葉に局所的脳血流低下を認めた ${ }^{3)}$. わ れわれも, 術後 1 力月目のXe-SPECTで前頭葉で安静時 脳血流の有意な低下を認めた。

したがって，画像上明らかな脳損傷や硬膜下液貯留の異 常所見は, 術後早期の意識障害など神経症状や術後の高次 脳機能の悪化を 3 割前後と高頻度引き起こし, さらに脳血 流障害にも関与して, 一部の症例で高次脳機能障害を後遺 すると思われた．多くは一過性であるが，これらの術後合 併症を認識して減らすことが, より厳密な意味での治療評 価に耐えうる成績につながると考えられた。

瘤の部位別に検討すると, ACoA 瘤と MCA 瘤に術後早 期の神経症状と高次脑機能悪化や，画像上の異常所見が多 かった。過去の報告でも ACoA 瘤では, 術中の脳圧排に よる影響で高次脳機能障害や脳循環の障害をきたすことが 多( ${ }^{3)}$ 9-12) 14)。しかし，今回 mRSに影響したのは，これ らの異常所見の少ない動脈輪近傍部 ICA 瘤であり，未破 裂脳動脈瘤に直達手術を選択する際には, 部位別の合併症 発現頻度も重要な基準であろう。

\section{結 語}

未破裂無症候性脳動脈瘤への直達手術では, MRI上の 脳損傷や硬膜下液貯留が, 多くは一過性であるが, 神経症 状や高次脳機能に影響し, 脳血流障害を起こすことが示さ れた。いずれも，神経後遺症につながる可能性を認識した うえで, 手術適応およびアプローチ方法を決定し, 慎重か つ丁寧な手術操作を心がけることが望まれる.

高次脳機能評価を実施していただきました臨床心理士の 小西佳子先生, 久保由美子先生に深謝いたします。

\section{文献}

1）鐙谷武雄，佐山一郎，朝倉 健，ほか：開頭術の脳循環代 
謝に及ぼす影響一PETによる未破裂脳動脈瘤根治術での検 討一. 脳外 18: 837-844, 1990

2) Brilstra EH, Rinkel GJE, van der Graaf Y, et al: Treatment of intracranial aneurysms by embolization with coils. A systematic review. Stroke 30: 470-476, 1999

3) Fukunaga A, Uchida K, Hashimoto J, et al: Neuropsychological evaluation and cerebral blood flow study of 30 patients with unruptured cerebral aneurysms before and after surgery. Surg Neurol 51: 132-139, 1999

4）波出石弘, 安井信之, 鈴木明文：未破裂脳動脈瘤の外科的 治療における問題点. 脳外 19: 945-949, 1991

5) Jenkins A, Hadley DM, Teasdale GM, et al: Magnetic resonance imaging of acute subarachnoid hemorrhage. $J$ Neurosurg 68: 731-736, 1988

6) Kanno I, Lassen NA: Two methods for calculating regional cerebral blood flow from emission computed tomography of inert gas concentrations. J Comput Assist Tomogr 3: 71-76, 1979

7) King JT Jr, Berlin JA, Flamm ES: Morbidity and mortality from elective surgery for asymptomatic, unruptured, intracranial aneurysms: A meta-analysis. J Neurosurg 81: 837-842, 1994

8) Kivisaari RP, Salonen O, Ohman J: Basal brain injury in aneurysm surgery. Neurosurgery 46: 1070-1076, 2000

9）小林正人, 高山秀一, 菅 貞郎, ほか：未破裂脳動脈瘤術 前後の大脳半球の脳代謝および高次脳機能の変化- $1 \mathrm{H}-\mathrm{MR}$ spectroscopy および WAIS-Rを用いた検討一. 脳外 28 : 691-698, 2000
10）小松洋治，益子良太，土田幸広，ほか：未破裂脳動脈瘤手 術の認知機能への影響および予後因子の検討. 脳外誌 10 : 654-659, 2001

11）久門良明, 大上史朗, 岡 芳久, ほか：未破裂脳動脈瘤の 治療一高次脳機能評価の重要性一. 脳卒中の外科 31: 436441, 2003

12）久門良明, 福本真也, 渡邊英昭, ほか：未破裂・無症候性 脳動脈瘤の治療一手術成績と今後の課題について一. 脳卒 中の外科 33: 435-441, 2005

13）間中 浩，坂井信幸，永田 泉，ほか：無症候性未破裂脳 動脈瘤の治療成績 · 術後合併症. 脳卒中の外科 29: 414-419, 2001

14) Ohue S, Oka $Y$, Kumon $Y$, et al: Importance of neuropsychological evaluation after surgery in patients with unruptured cerebral aneurysms. Surg Neurol 59: 269-276, 2003

15) Otawara Y, Ogasawara K, Ogawa A, et al: Cognitive function before and after surgery in patients with unruptured intracranial aneurysm. Stroke 36: 142-143, 2005

16）品川不二郎, 小林重雄, 藤田和弘, ほか : 日本版 WAIS-R 成人知能検査法. 日本文化科学社, 1998

17) Tuffiash E, Tamargo RJ, Hillis AE: Craniotomy for treatment of unruptured aneurysms is not associated with long-term cognitive dysfunction. Stroke 34: 2195-2199, 2003

18) Yasui N, Nishimura H: Surgical treatment of unruptured intracranial aneurysms over the past 22 years. Neurol Med Chir (Tokyo) 44: 155-163, 2004 